\title{
Characterization of the human and mouse genes encoding the tuberoinfundibular peptide of 39 residues, a ligand of the parathyroid hormone receptor family
}

\author{
I A Hansen, O Jakob, S Wortmann, T Arzberger ${ }^{1}$, B Allolio \\ and $\mathbf{E}$ Blind \\ Department of Medicine (Endocrinology), University of Würzburg, Josef-Schneider-Strasse 2, D-97080 Würzburg, Germany \\ ${ }^{1}$ Department of Pathology, University of Würzburg, Würzburg, Germany \\ (Requests for offprints should be addressed to E Blind; Email: eberhard.blind@mail.uni-wuerzburg.de)
}

\begin{abstract}
The polypeptide TIP39 (tuberoinfundibular peptide of 39 residues) is a potent activator of the parathyroid hormone (PTH)-2 receptor (P2R) and an antagonist of the PTH-1 receptor (P1R). To clarify its possible physiological function(s), we studied its interaction with the human P1R and P2R and examined the expression of TIP39 in man and mouse. To find out possible sites of this ligand interaction in the organism, we identified the genes encoding the TIP39 protein precursors of Homo sapiens and Mus musculus in the databases of the human and mouse genome projects respectively. We then obtained the full-length cDNAs of both species by RACE-PCR. The deduced TIP39 preprohormones consist of an N-terminal 30 amino acid (aa) signal peptide followed by a 29 aa TIP39 precursor-related peptide, an Arg-Arg processing site, and the actual 39 aa TIP39 sequence. The first 23 aa of the actual TIP39 sequence, thought to contain the P2R receptor activation site, are identical in man and mouse and thus phylogenetically conserved. By contrast, the 16 aa C-terminal portion showed a higher degree of diversity (75\% aa identity). By using RT-PCR, TIP39 was found to be highly expressed in human central nervous system tissues, trachea, fetal liver, and, to a lesser degree, in human heart and kidney. Using in situ hybridization,
\end{abstract}

TIP39 mRNA expression was revealed in various areas of the mouse brain. In a homologous human cell model using human embryonic kidney 293 cells stably transfected with human P1R and P2R, human TIP39 did bind to P1R with moderate affinity $\left(\mathrm{IC}_{50} \sim 10^{-7}-10^{-6} \mathrm{M}\right)$, but showed higher affinity binding to $\mathrm{P} 2 \mathrm{R}\left(\mathrm{IC}_{50} \sim 10^{-8} \mathrm{M}\right)$, comparable to the affinity of human $\mathrm{N}$-terminal PTH (hPTH(1-34)) to this receptor. In P2R-transfected cells, the cAMP pathway was activated more efficiently $(\sim 10-$ fold) by TIP39 as a ligand compared to hPTH(1-34). In P1R-transfected cells, only hPTH(1-34) but not TIP39 was able to elicit a cAMP response, but TIP39 was able to directly antagonize the cAMP-stimulating effect of $\mathrm{hPTH}(1-34)$ on this receptor. In conclusion, we could show a possible function of TIP39 for the human organism as a potent activator of $\mathrm{P} 2 \mathrm{R}$ (e.g. in brain) as well as an antagonist of the action of PTH and/or PTH-related protein on P1R (e.g. in bone and kidney). The physiological role of TIP39 in calcium metabolism with regard to these actions remains to be determined. The tools developed in this work will allow us to investigate the possible role of TIP39 as a locally or systemically secreted ligand modulating the function of the PTH receptor family.

Journal of Endocrinology (2002) 174, 95-102

\section{Introduction}

The polypeptide TIP39 (tuberoinfundibular peptide of 39 residues) has been discovered recently in bovine hypothalamus (Usdin et al. 1999b) as a third member of the parathyroid hormone (PTH) ligand family, which now consists of PTH, PTH-related protein (PTHrP) and TIP39 (Usdin et al. 2000). Whereas PTH plays a major role in calcium metabolism and PTHrP regulates bone and cartilage development (among other functions), the biological function of TIP39 is largely unknown. It shows a limited homology with PTH, only 9 out of 39 residues are identical in the bovine amino acid (aa) sequence (Usdin et al. 1999b, Piserchio et al. 2000). TIP39 is a potent activator of the PTH-2 receptor (P2R), the physiological function of which is also unknown at present (Usdin 2000). However, TIP39 also acts as an antagonist on the PTH-1 receptor (P1R), to an extent which varies in different species (Hoare et al. 2000). TIP39 has been isolated from bovine hypothalamus due to its capability of activating the P2R. Since the publication of this discovery in November 1999 (Usdin et al. 1999b), there are still only very few data about the possible function(s) of this peptide and where it might be expressed in the organism, besides 
the hypothalamus. A possible function of TIP39 in this hypothalamic region has been suggested recently by experiments showing some influence on hypothalamopituitary axes (Ward et al. 2001).

To clarify its possible physiological function(s), we studied the interaction of human TIP39 in a homologous human model system with the human P1R and human P2R and examined the expression of TIP39 in man and mouse.

\section{Materials and Methods}

Cell lines, peptides and animals

The cDNA of P1R (kindly provided by Dr Harald Jüppner, Boston, MA, USA) and P2R (kindly provided by Dr T Usdin, Bethesda, MD, USA) were subcloned into the expression vector pCEP4 (Invitrogen, San Diego, CA, USA) and used to generate human embryonic kidney (HEK) 293 cells stably expressing the receptor proteins, as described (Blind et al. 1995). The cells were maintained in DMEM medium with Glutamax, containing 10\% fetal calf serum, $100 \mathrm{U} / \mathrm{ml}$ penicillin $\mathrm{G}$, and $100 \mu \mathrm{g} / \mathrm{ml}$ streptomycin in a humidified atmosphere of $95 \%$ air $/ 5 \% \mathrm{CO}_{2}$ at $37^{\circ} \mathrm{C}$. Human PTH(1-34) (hPTH(1-34)) was purchased from Bachem (Heidelberg, Germany). TIP39 was custom synthesized by Immundiagnostik (Bensheim, Germany) using the published aa sequence (Usdin et al. 1999b).

Adult male CD-1 mice were purchased from Charles River Breeding Laboratories (Sulzfeld, Germany). Animals were kept under standard laboratory conditions with a $12 \mathrm{~h}$ light: $12 \mathrm{~h}$ darkness cycle. All efforts were made to minimize both the suffering and number of animals used and all procedures were performed according to the accepted standards of good animal care.

\section{Radioligand binding assays}

Competitive binding studies were carried out in intact cell assays by displacement of the radioactive ligand $\left[{ }^{125} \mathrm{I}\right]-$ $\mathrm{Nle}^{8,21}-\mathrm{Tyr}^{34}$-rat PTH(1-34)-amide (NEN, Boston, MA, USA). Cells were grown for 3 days in 24-well plates to confluence, exposed to serum-free assay medium (DMEM containing $0 \cdot 1 \%$ BSA and $1 \mathrm{mM}$ Hepes) for $1 \mathrm{~h}$ and incubated in assay medium containing 50000 c.p.m. radioactive ligand and various concentrations of unlabeled $\mathrm{hPTH}(1-34)$ or synthetic TIP39 at room temperature for $1 \mathrm{~h}$. The cells were washed three times with ice-cold medium and then dissolved in $1 \mathrm{ml} 1 \mathrm{M} \mathrm{NaOH}$ for measurement of cell-associated ${ }^{125} \mathrm{I}$ in a $\gamma$-counter.

\section{Measurement of total inositol phosphate (IP) turnover and of accumulated intracellular $C A M P$}

The determination of accumulated total IPs was carried out in cells metabolically prelabeled with $\left[{ }^{3} \mathrm{H}\right]$ myoinositol
(Amersham, Freiburg, Germany) as described previously (John et al. 2001). To improve detectability of rather small degrees of activation of this pathway, the protein kinase inhibitors H-89 $(30 \mu \mathrm{M})$ and GF 109203X $(6 \mu \mathrm{M})$ (both from Bachem) were added, since we had shown previously that blocking protein kinases $\mathrm{A}$ and $\mathrm{C}$ with these substances resulted in an enhanced IP response (Blind et al. 1996).

To stimulate intracellular formation of cAMP, cells were incubated in 12-well plates with DMEM medium containing 1\% BSA, $20 \mathrm{mM}$ Hepes buffer and $1 \mathrm{mM}$ 3-isobutyl-1-methylxanthine at $37^{\circ} \mathrm{C}$ for 15 min together with the test substances. After removal of the supernatant, accumulated intracellular cAMP was extracted with $1 \mathrm{ml}$ 95\% ethanol, $\mathrm{pH} 3$. After $2 \mathrm{~h}$, the alcohol was removed by evaporation and cAMP measured by RIA (Beckmann Coulter, Unterschleissheim, Germany).

\section{Data analysis}

Data for ligand-stimulated second messenger accumulation and inhibition of radioligand binding were analyzed using the software package Prism (GraphPad Software, Inc., San Diego, CA, USA), which was also used to calculate $\mathrm{EC}_{50}$ and $\mathrm{IC}_{50}$ values.

\section{Isolation of RNA from solid tissues and RACE}

Total RNA was isolated by a commercially available modification (TRIzol; Invitrogen, Karlsruhe, Germany) of the one-step phenol/guanidinium thiocyanate method (Chomczynski \& Sacchi 1987). Poly A ${ }^{+}$RNA was isolated using the Oligotex mRNA Mini Kit (Qiagen, Hilden, Germany).

RACE was performed using the SMART RACE cDNA Amplification Kit (Clontech, Alameda, CA, USA) following the manufacturer's instructions. One microgram of poly $\mathrm{A}^{+}$RNA was used as starting material. The following synthetic oligonucleotides were used as primers for RACE-PCRs: Homo sapiens 5'-RACE (5'-CTGCAC GGTAGGGGACTGTGCGGGAAGCTGG-3'), Homo sapiens 3'-RACE (5'-ATGGAGACCCGCCAGGTG TCCAGGAGCCCT-3'); Mus musculus 5'-RACE (5'AGGCGCAGTCGCAGTGCGACAGGCTC-3'), Mus musculus 3'-RACE (5'-ATGGAGACCTGCCAGATGT CCAGGACGCCC $\left.-3^{\prime}\right)$. RACE products were analyzed in $1.5 \%$ agarose gels. Isolated bands were cut out of the gel and agarose was removed using Ultrafree-DA spin columns (Millipore, Eschborn, Germany). The cDNAs were inserted into the PCRII-TOPO vector (Invitrogen) following the manufacturer's instructions. Sequencing was performed by Toplab (Martinsried, Germany).

\section{Labeling of RNA probes with digoxigenin-UTP (DIG-UTP)} by in vitro transcription

In vitro transcribed RNA (cRNA) was synthesized from cDNA fragments cloned into the plasmid PCRII-TOPO 
(Invitrogen) using T7 or SP6 polymerase respectively. Plasmids were linearized by digestion with an appropriate restriction enzyme. Reactions were performed according to protocols of the DIG RNA labeling kit (Roche, Basel, Switzerland).

\section{In situ hybridization on cryosections}

Total brains of adult mice were dissected, carefully frozen with dry ice powder and stored at $-80{ }^{\circ} \mathrm{C}$. Cryosections $(10 \mu \mathrm{m})$ were transferred to SuperFrostPlus microscope slides (Roth, Karlsruhe, Germany) and fixed for $15 \mathrm{~min}$ in $4 \%$ para-formaldehyde/PBS at $4{ }^{\circ} \mathrm{C}$. In situ hybridization was performed as described in the Nonradioactive In Situ Hybridization Application Manual (Roche Molecular Biochemicals, 2nd edition). The reactive structures were visualized by colorimetric reaction (4-nitroblue tetrazolium chloride/5-bromo-4-chloro-3-indolyl-phosphate). The specimens were mounted in Aquamount (Dako, Hamburg, Germany) and analyzed under the microscope.

\section{RT-PCR}

The reactions were carried out using total RNA $(250 \mu \mathrm{g})$ as template and the Qiagen OneStep RT-PCR Kit (Qiagen) according to the manufacturer's instructions. The PCR products were analyzed in 1.5\% agarose gels stained with ethidium bromide. The following synthetic oligonucleotide pairs were used as primers for Mus musculus, 5'-CTGCACGGTAGGGGGTCCTGTAGGA GGCTGG-3' and 5'-AGGCGCAGTCGCAGTGCGA CAGGCTC-3', and for Homo sapiens, 5'-CTGCAC GGTAGGGGACTGTGCGGGAAGCTGG-3' and $5^{\prime}-$ CGCAGTCCGGAGCGCAGGGCATGGTC-3'.

\section{Nucleotide and a sequence analysis}

Genome searches were performed using TBLASTN at the NCBI databases (http://www.ncbi.nlm.nih.gov/); sequence similarities were studied using Clustalw at EMBL (http://www2.ebi.ac.uk/clustalw/).

\section{Results}

Characterization of the gene encoding TIP39

A database search in the human genome using the aa sequence described in the literature revealed a TIP39 gene locus on the long arm of chromosome 19 at band 19q13.3. In the mouse genome a sequence derived from the NCBI mouse genome database was identified. Starting with templates of mouse and fetal human brain, we obtained human and murine cDNAs by RACE-PCR (submitted to GenBank and available under the GenBank accession numbers: AY037555 and AC073740). An alignment of the nucleotide sequences of the human and murine cDNAs revealed $80 \%$ identity. The human cDNA consists of a $5^{\prime}$-untranslated sequence of $102 \mathrm{bp}$, an open reading frame of $300 \mathrm{bp}$, and $55 \mathrm{bp}$ of $3^{\prime}$-untranslated sequence containing a polyadenylation signal (Fig. 1A and B). The genes of both man and mouse consist of two exons separated by an intron at corresponding sites. Exon 1 encodes 43 aa of the TIP39 precursor protein, exon 2 encodes the remaining 57 aa (Fig. 1C).

A computational analysis (Nielsen et al. 1997) of the 100 aa prepro sequence indicates that the first 30 aa most probably function as a signal peptide that directs the polypeptide chain to the endoplasmatic reticulum. The TIP39 precursor also contains two possible cleavage sites (Arg-Arg motif with compatible adjacent residues). The first separates an intercalated peptide from the secreted peptide (Fig. 1D), the second is found at position 22/23 within the actual TIP39 sequence, suggesting that they may play a role in the processing of TIP39.

Comparison of the primary structure of the human and mouse preproTIP39 and the partially known bovine sequence using the Clustalw software shows a 100\% identity between Homo sapiens and Bos taurus within the actual TIP39 sequence. Man and mouse share $79 \%$ overall identity and $89 \%$ identity within the secreted TIP39 peptide itself (Fig. 1F). The identities of the signal peptides comprise $77 \%$, the intercalated peptides $68 \%$. The actual TIP39 sequence shows the highest degree of identity in the $\mathrm{N}$-terminal region.

\section{Distribution of TIP39 mRNA in man}

By RT-PCR we screened human tissues for TIP39 mRNA expression (Fig. 2). Using templates of fetal and adult tissues we obtained strong bands in fetal and adult brain, cerebellum and trachea. Furthermore, there was evidence for TIP39 mRNA synthesis in spinal cord, fetal liver, kidney and heart. No response was detected in adult liver, lung, placenta and adrenal gland.

\section{Expression of murine TIP39 $m R N A$ in mouse brain}

To evaluate the expression pattern of TIP39 mRNA, a DIG-labeled RNA probe was constructed and the distribution examined by in situ hybridization on cryosections from mouse brain (Fig. 3). A wide range of hybridization intensities was observed, with many positive neurons throughout all regions of the nervous system. In the cerebral cortex and subcortical areas, e.g. septal nuclei and caudate-putamen, many neurons were densely labeled whereas the glia cell-rich corpus callosum remained unstained. In the cerebellum, hybridization signals were found in Purkinje cells, and in cells of the molecular layer (probably basket and stellate cells), but were nearly absent in the neuron-rich granular cell layer. 


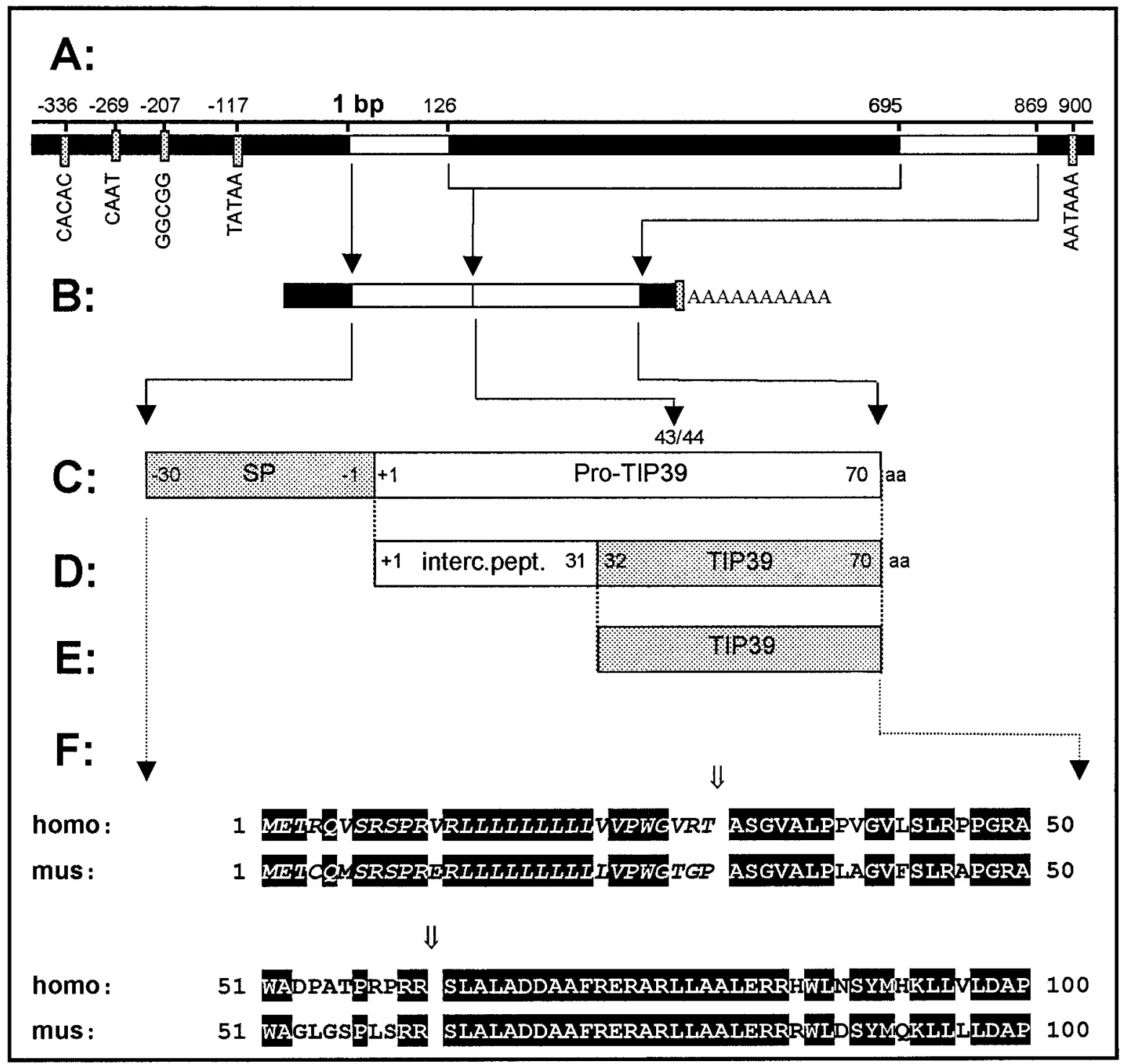

Figure 1 Scheme of the human TIP39 gene transcription, translation and posttranslational modifications and comparison of the deduced TIP39 preprohormones of Homo sapiens and Mus musculus. (A) TIP39 gene; conserved sequences of the promoter region and the polyadenylation signal sequence are in gray boxes, exons are white boxed, untranslated regions and the intron are black boxed. (B) TIP39 mRNA; untranslated regions are black boxed. (C) TIP39 preprohormone; the hydrophobic signal peptide (SP) is gray boxed. (D) TIP39 prohormone; intercalated peptide (interc. pept.) is white boxed, TIP39 core region is gray boxed. (E) Finally processed TIP39 peptide. (F) Deduced TIP39 preprohormones of Homo sapiens and Mus musculus; identical aa are black boxed, the signal peptides are shown in italic letters, presumed cleavage sites are marked with an arrow.

Comparison of PTH and TIP39 actions on the human PTH receptors

We directly compared ligand binding of human TIP39 and hPTH(1-34) to the human P2R and P1R in an intact cell radioligand assay as described above. In both P1Rtransfected and P2R-transfected cell lines, the peptides were able to displace the radioactive ligand (Fig. $4 \mathrm{~A}$ and B). Non-specific binding was less than $20 \%$ of the total amount of tracer bound. Untransfected HEK 293 cells showed no specific binding of the radioligand (data not shown). hPTH(1-34) did bind to both human PTH receptor-transfected cell lines with similar affinities (P1R: $\mathrm{IC}_{50}=19 \mathrm{nM}$; P2R: $\left.\mathrm{IC}_{50}=16 \mathrm{nM}\right)$. Binding affinity of TIP39 was moderate with $\mathrm{P} 1 \mathrm{R} \quad\left(\mathrm{IC}_{50}=333 \mathrm{nM}\right)$. It showed higher binding affinity to $\mathrm{P} 2 \mathrm{R}\left(\mathrm{IC}_{50}=11 \mathrm{nM}\right)$, comparable to the affinity of $\mathrm{hPTH}(1-34)$ for both receptors (Fig. 4A and B). 


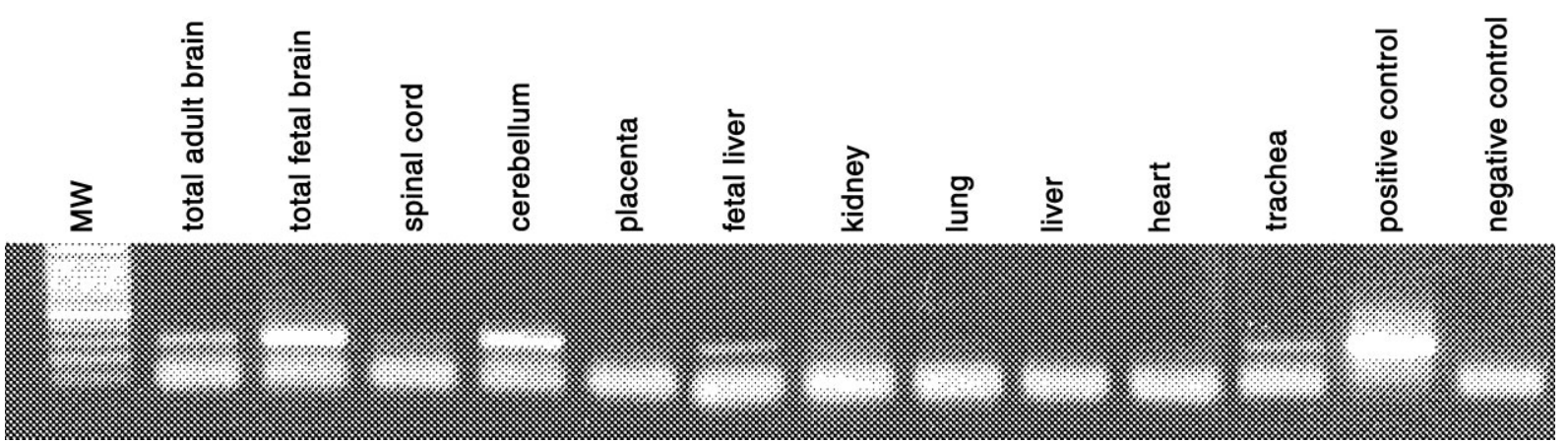

Figure 2 Specific distribution of TIP39 mRNA in various human tissues. The blot shows RT-PCR results obtained by amplification of a 300 bp cDNA fragment (upper band) The lower band represents excessive primer. A plasmid containing the full-length human TIP39 cDNA was used as a positive control. MW: molecular weight marker. The negative control reaction was performed by omitting template RNA.

The activation of the cAMP signaling pathway of P1R and P2R was measured by standard RIA after incubation with increasing concentrations of hPTH(1-34) and TIP39. The P1R could only be activated by hPTH(1-34) $\left(\mathrm{EC}_{50}=0 \cdot 21 \mathrm{nM}\right)$, whereas TIP39 in concentrations of up to $1 \mu \mathrm{M}$ showed no detected increase in accumulated intracellular cAMP (Fig. 4C). In P2R-transfected cells, the cAMP dose-response curve was shifted about 10-fold to the left with TIP39 as a ligand, compared to hPTH $(1-34)\left(\mathrm{EC}_{50}=0.36 \mathrm{nM}\right.$ and $3.50 \mathrm{nM}$ respectively). The maximal increase in cAMP accumulation was similar with both peptides (Fig. 4D).

Additionally, the activation of the phospholipase C pathway was estimated by measuring ligand-induced IP hydrolysis. Incubation with $3 \mu \mathrm{M}$ hPTH(1-34) caused a strong increase in intracellular total IP (about 10-fold) in P1R-transfected cells and a small increase (about 2-fold) in P2R-transfected cells. TIP39, however, was not able to elicit a response of the IP signaling pathway in either cell line (data not shown).

To test the antagonistic activity of TIP39 on P1R directly, we exposed P1R-transfected cells to increasing amounts of TIP39 up to $10 \mu \mathrm{M}$ in the presence of $0 \cdot 25 \mathrm{nM}$ hPTH(1-34). TIP39 almost completely inhibited agonist-induced cAMP accumulation with an $\mathrm{IC}_{50}$ value of half-maximal inhibition of approximately $1 \mu \mathrm{M}$ (Fig. 4E).

\section{Discussion}

TIP39 may exert its biological function via two different mechanisms, either by inhibiting the action of $\mathrm{PTH}$ and/or PTHrP on P1R, or by acting independently on $\mathrm{P} 2 \mathrm{R}$. We have shown in our homologous human cell model system that human TIP39 acts as a competitive antagonist to the biologically active part of $\mathrm{hPTH}$ $(\mathrm{hPTH}(1-34))$ on the human P1R. Additionally, we showed for the first time that TIP39, unlike PTH on P1R, does not activate the IP signaling pathway in P1R or P2R. Our results are in accord with published results of similar model systems, often using heterologous systems with ligands, cells or receptors from other species, however (Hoare et al. 1999, 2000, Jonsson et al. 2001). It is thus conceivable that locally secreted TIP39 could inhibit the action of systemically circulating PTH, especially since the physiological levels of the bioactive part of this peptide are rather low in the circulation, in the range $0 \cdot 5-3 \mathrm{pM}$ (Gao et al. 2001). This would be especially relevant for the classic target organs of PTH in calcium homeostasis, bone and kidney. However, there are no published data on whether TIP39 is expressed in these organs. We were able to show that TIP39 mRNA is indeed present in the kidney, when looked at by RT-PCR. Whether TIP39 acts as a competitor of $\mathrm{P} 1 \mathrm{R}$ or as an activator for $\mathrm{P} 2 \mathrm{R}$ in these tissues is unclear at present. Some evidence comes from investigations with $\mathrm{P} 2 \mathrm{R}$, however. Although $\mathrm{P} 2 \mathrm{R}$ mRNA was not detected by Northern blot in renal tissue (Usdin et al. 1995), Usdin et al. (2000) could show small numbers of cells near the vascular pole of kidney glomeruli to be P2R-positive by antibody staining and by in situ hybridization for P2R mRNA. These cells possibly belong to the juxtaglomerular apparatus, leading to speculations that their function might involve regulation of blood pressure as a target of a renin-releasing factor, which has been shown to be released from the hypothalamus and which is indistinguishable from TIP39 by size (Urban et al. 1992). We have no data yet on whether TIP39 is expressed in bone. It is also not clear at present whether $\mathrm{P} 2 \mathrm{R}$, as the other possible target besides the osteoblastic $\mathrm{P} 1 \mathrm{R}$, is present in bone, since no such study has been performed in this tissue so far. Attempts to detect P2R mRNA by RT-PCR in bone-derived cells have yielded equivocal results (Usdin et al. 2000).

Thyroid C-cells are another tissue linked to calcium metabolism where P2R was found to be expressed (Usdin 

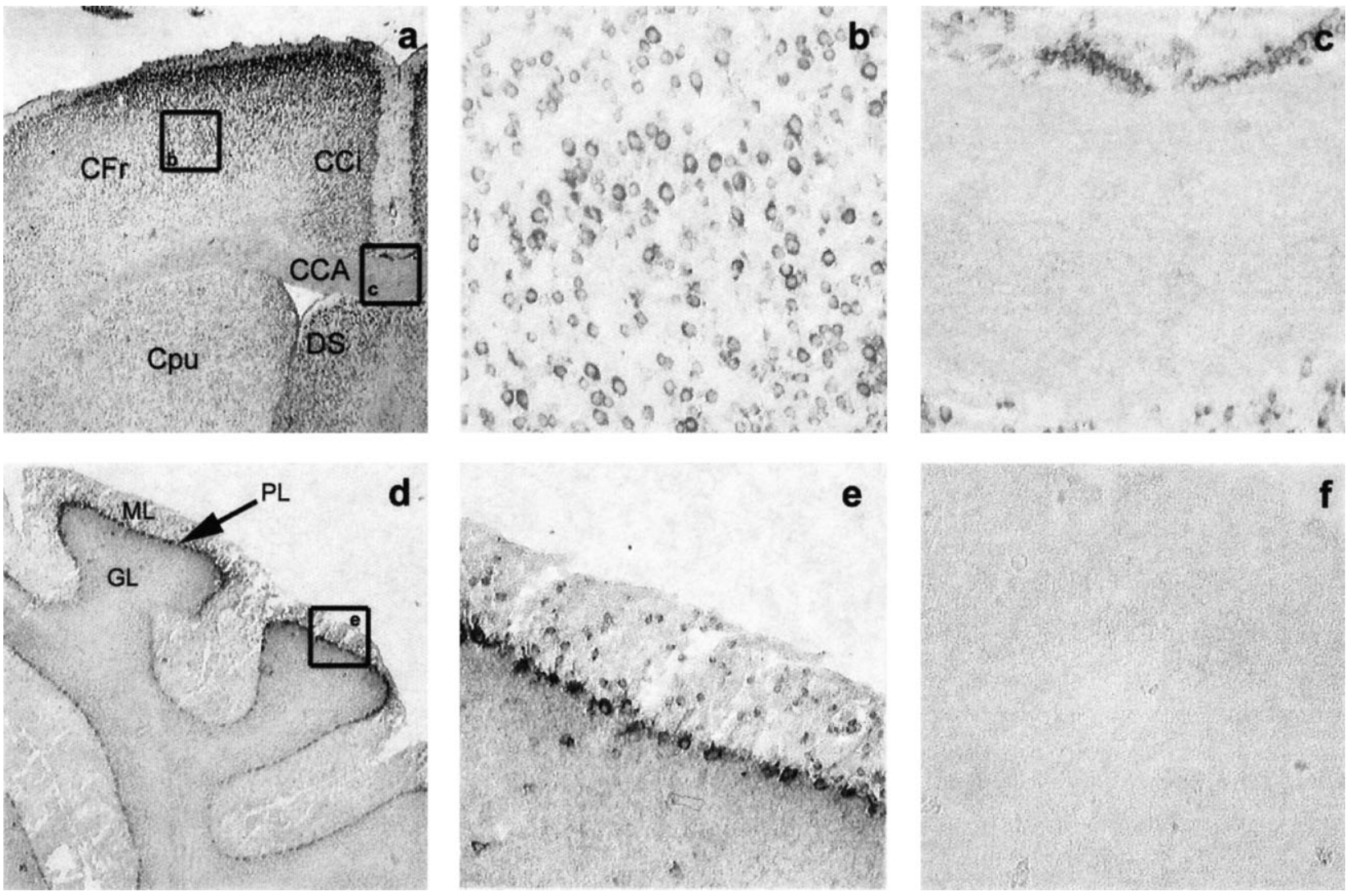

Figure 3 Distribution of TIP39 mRNA in coronal sections of mouse brains visualized by in situ hybridization. A broad range of hybridization intensities was observed, with many positive neurons throughout all regions of the central nervous system. (a) Overview of a mouse brain cryosection $(\times 12 \cdot 5)$. CCA, corpus callosum; CCi, cingulate cortex; Cpu, caudate-putamen; CFr, frontal cortex; DS, dorsal septal nucleus. (b) Inset of (a), showing cortical neurons in different layers stained with various intensity $(\times 100)$. (c) Inset of (a), showing absence of TIP39 mRNA in glia cells of the corpus callosum $(\times 100)$. (d) Overview of mouse cerebellum cryosection $(\times 12 \cdot 5)$. GL, granular cell layer; PL, Purkinje cell layer; ML, molecular layer. (e) Inset of (d), showing distinct staining of Purkinje cells and of cells in the molecular layer, whereas staining was largely absent in the granular cell layer $(\times 100)$. $(\mathrm{f})$ Cortical area corresponding to the area shown in (b) $(\times 100)$. In situ hybridization was performed using a DIG-labeled TIP39 sense RNA probe as a negative control $(\times 12 \cdot 5)$.

et al. 1999a). C-cells were specifically labeled by a P2R-specific antibody whereas the surrounding majority of follicular thyroid cells were negative. Since C-cells also express the calcium sensing receptor and respond with secretion of bioactive peptides upon an increase in serum calcium, there might be a link of $\mathrm{P} 2 \mathrm{R}$ to the regulation of calcium metabolism. We have no data yet, however, on whether TIP39 is involved in this process.

As estimated by Northern blot, P2R is expressed at particularly high levels in brain. Unlike in peripheral tissue, TIP39 seems to be the single probable ligand of this receptor in brain, since investigators have failed to detect PTH mRNA in rat brain tissue (Usdin 1997), and since most regions of cerebral $\mathrm{P} 2 \mathrm{R}$ expression would not be reached by PTH from the blood stream. The pattern of $\mathrm{P} 2 \mathrm{R}$ distribution in the rat nervous system has been extensively studied recently (Wang et al. 2000). It shows a widespread expression, most often in discrete groups of neurons, with an especially high level of expression in hypothalamic, limbic and sensory areas. The pattern of distribution of TIP39 expression found in our studies seemed to differ significantly, with TIP39 showing a distinct distribution pattern, which was, however, also widespread within various cerebral regions. A more detailed study is, therefore, needed to locate TIP39 expression in comparison to the $\mathrm{P} 2 \mathrm{R}$ expression pattern.

We could detect TIP39 mRNA in human spinal cord. The rat $\mathrm{P} 2 \mathrm{R}$ was shown to be expressed there, too, localized to the superficial dorsal horn, spinal trigeminal tract and nucleus. Because these areas receive their principal input from sensory neurons involved in pain perception (Usdin et al. 1999b), this colocalization might hint at a possible TIP39/P2R interaction modulating nociceptive function.

An analysis of the deduced aa sequence of the TIP39 preprohormones of man and mouse clearly shows the 

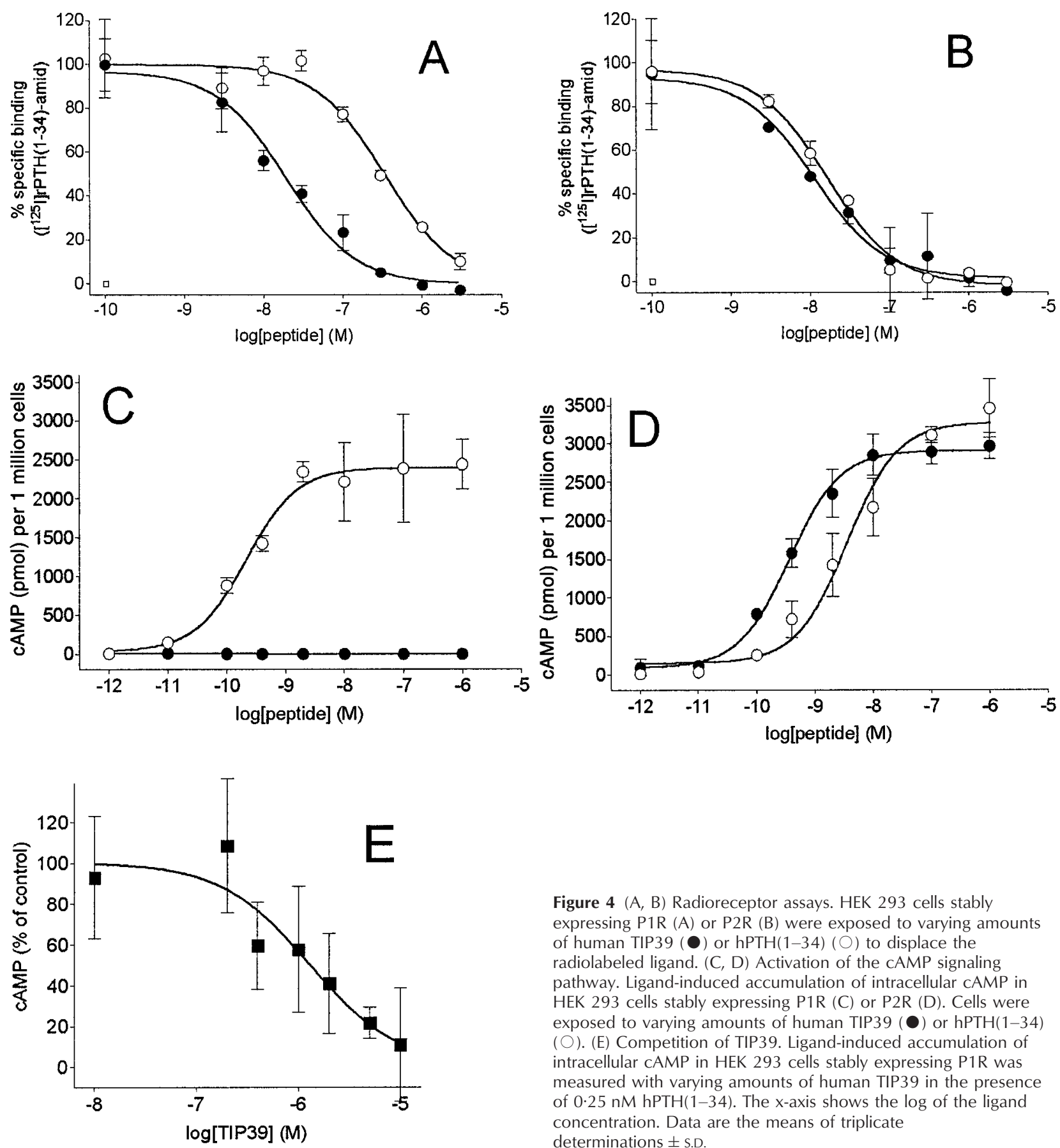

features of secreted neuropeptides with a characteristic signal peptide for the secretory pathway and a dibasic cleavage site for subtilisin-like endoproteases to process the prohormone (Hosaka et al. 1991).

The overall structural features of the preprohormones of TIP39, PTH and PTHrP - signal peptide, intercalated

peptide and hormone - are identical. However, the intercalated peptide of TIP39 comprises 31 aa, and is much longer than the predicted intercalated peptides of PTH and PTHrP ( 8 aa). The overall aa sequence similarity between these three ligands is very low, whereas the tertiary structure of the portion interacting with $\mathrm{P} 1 \mathrm{R}$ 
seems similar (Piserchio et al. 2000). PTH, PTHrP and TIP39 thus seem to have only a distant phylogenetic relationship.

The N-terminal alpha helix of TIP39, which seems to be responsible for $\mathrm{P} 2 \mathrm{R}$ activation, is identical in man and mouse, whereas the C-terminal alpha helix, which is important for receptor binding (Piserchio et al. 2000), differs in four aa positions, being apparently responsible for the different binding properties of murine and human TIP39 (Goold et al. 2001).

There is no experimental evidence yet that the predicted dibasic cleavage site found between the two alpha helices is functional. One might speculate that it is involved in the degradation and/or inactivation of TIP39, or that the possible cleavage products have bioactivity on their own. While it seems certain that TIP39 is in fact a secreted peptide, it is entirely unknown whether detectable amounts of TIP39 can be found in plasma and whether therefore this peptide could act systemically.

In conclusion, we could show that in the human organism TIP39 is expressed in various tissues and might function as a potent activator of $\mathrm{P} 2 \mathrm{R}$ (e.g. in brain) as well as an antagonist of the action of PTH and/or PTHrP on P1R (e.g. in bone and kidney). The physiological role of TIP39 in calcium metabolism with regard to these actions, e.g. as a locally secreted ligand modulating the function of the PTH receptor family, remains to be determined, however. The tools developed in this work will allow further investigation of the function of this new ligand of the PTH receptor family.

\section{Acknowledgements}

I A $\mathrm{H}$ and $\mathrm{O} \mathrm{J}$ contributed equally to this work. This work was supported by a grant from the Deutsche Forschungsgemeinschaft (Bl 291/4-3) to E B.

\section{References}

Blind E, Bambino T \& Nissenson R 1995 Agonist-stimulated phosphorylation of the G-protein-coupled receptor for parathyroid hormone and parathyroid hormone-related protein. Endocrinology $1364271-4277$

Blind E, Schroth J, Nissenson R, Ziegler R \& Raue F 1996 Signaling properties of a C-terminally truncated $\mathrm{PTH} / \mathrm{PTHrP}$ receptor expressed in HEK 293 cells. Journal of Bone and Mineral Research 11 (Suppl 1) S307 [Abstract].

Chomczynski P \& Sacchi N 1987 Single-step method of RNA isolation by acid guanidinium thiocyanate-phenol-chloroform extraction. Analytical Biochemistry 162 156-159.

Gao P, Scheibel S, D'Amour P, John MR, Rao SD, Schmidt-Gayk H \& Cantor TL 2001 Development of a novel immunoradiometric assay exclusively for biologically active whole parathyroid hormone 1-84: implications for improvement of accurate assessment of parathyroid function. Journal of Bone and Mineral Research $\mathbf{1 6}$ 605-614.
Goold CP, Usdin TB \& Hoare SR 2001 Regions in rat and human parathyroid hormone $(\mathrm{PTH}) 2$ receptors controlling receptor interaction with PTH and with antagonist ligands. Journal of Pharmacology and Experimental Therapeutics 299 678-690.

Hoare SR, Bonner TI \& Usdin TB 1999 Comparison of rat and human parathyroid hormone 2 ( $\mathrm{PTH} 2$ ) receptor activation: $\mathrm{PTH}$ is a low potency partial agonist at the rat $\mathrm{PTH} 2$ receptor. Endocrinology 140 4419-4425.

Hoare SR, Clark JA \& Usdin TB 2000 Molecular determinants of tuberoinfundibular peptide of 39 residues (TIP39) selectivity for the parathyroid hormone-2 (PTH2) receptor. N-terminal truncation of TIP39 reverses PTH2 receptor/PTH1 receptor binding selectivity. Journal of Biological Chemistry 275 27274-27283.

Hosaka M, Nagahama M, Kim WS, Watanabe T, Hatsuzawa K, Ikemizu J, Murakami K \& Nakayama K 1991 Arg-X-Lys/Arg-Arg motif as a signal for precursor cleavage catalyzed by furin within the constitutive secretory pathway. Journal of Biological Chemistry 266 12127-12130.

John M, Bösel J, Breit S, Wickert H, Ziegler R \& Blind E 2001 Changing serine- 485 to alanine in the opossum parathyroid hormone (PTH)/PTH-related peptide receptor enhances PTH stimulation of phospholipase $\mathrm{C}$ in a stably transfected human kidney cell line: a useful model for PTH-analog screening? Bone $\mathbf{2 8}$ 182-186.

Jonsson K, John M, Gensure R, Gardella T \& Juppner H 2001 Tuberoinfundibular peptide 39 binds to the parathyroid hormone (PTH)/PTH-related peptide receptor, but functions as an antagonist. Endocrinology 142 704-709.

Nielsen H, Engelbrecht J, Brunak S \& von Heijne G 1997 Identification of prokaryotic and eukaryotic signal peptides and prediction of their cleavage sites. Protein Engineering 10 1-6.

Piserchio A, Usdin T \& Mierke DF 2000 Structure of tuberoinfundibular peptide of 39 residues. Journal of Biological Chemistry 275 27284-27290.

Urban JH, Brownfield MS, Levine JE \& Van de Kar LD 1992 Distribution of a renin-releasing factor in the central nervous system of the rat. Neuroendocrinology 55 574-582.

Usdin TB 1997 Evidence for a parathyroid hormone-2 receptor selective ligand in the hypothalamus. Endocrinology 138 831-834.

Usdin TB 2000 The PTH2 receptor and TIP39: a new peptidereceptor system. Trends in Pharmacological Sciences 21 128-130.

Usdin TB, Gruber C \& Bonner TI 1995 Identification and functional expression of a receptor selectively recognizing parathyroid hormone, the PTH2 receptor. Journal of Biological Chemistry $\mathbf{2 7 0}$ $15455-15458$.

Usdin TB, Hilton J, Vertesi T, Harta G, Segre G \& Mezey E 1999a Distribution of the parathyroid hormone 2 receptor in rat: immunolocalization reveals expression by several endocrine cells. Endocrinology 140 3363-3371.

Usdin TB, Hoare SR, Wang T, Mezey E \& Kowalak JA 19996 TIP39: a new neuropeptide and PTH2-receptor agonist from hypothalamus. Nature Neuroscience 2 941-943.

Usdin TB, Wang T, Hoare SR, Mezey E \& Palkovits M 2000 New members of the parathyroid hormone/parathyroid hormone receptor family: the parathyroid hormone 2 receptor and tuberoinfundibular peptide of 39 residues. Frontiers in Neuroendocrinology 21 349-383.

Wang T, Palkovits M, Rusnak M, Mezey E \& Usdin TB 2000 Distribution of parathyroid hormone-2 receptor-like immunoreactivity and messenger RNA in the rat nervous system. Neuroscience 100 629-649.

Ward HL, Small CJ, Murphy KG, Kennedy AR, Ghatei MA \& Bloom SR 2001 The actions of tuberoinfundibular peptide on the hypothalamo-pituitary axes. Endocrinology 142 3451-3456.

Received 10 January 2002

Accepted 11 March 2002 